\title{
Galanin immunoreactivity in the brain of the desert lizard Uromastyx acanthinura during activity season
}

\author{
Sadjia Benmansour Hammouche1, Mohammed Bennis ${ }^{2}$ \\ ${ }^{1}$ Aride Area Research Laboratory, Biological Sciences Faculty, University of Sciences and \\ Technology of Houari Boumediene, Bab Ezzouar, Algeria \\ ${ }^{2}$ Pharmacology, Neurobiology and Comportement Laboratory, Departement of Biology, Sciences \\ Faculty, University of Cadi Ayyad, Marrakech, Morocco
}

\begin{abstract}
The distribution of galanin immunoreactive perikarya and nerve fibers in the brain of the desert lizard $U$. acanthinura was studied by means of immunofluorescence using an antiserum against rabbit galanin. The animals were captured during the activity season in March (wet season) just before reproduction period and in June (arid season) after ovulation period. Immunoreactive neurons were mostly detected in the mediobasal and the infundibular recess nuclei, the nucleus of the paraventricular organ, the paraventricular organ, the periventricular nucleus and in the anterior hypothalamus at the level of the periventricular nucleus, the paraventricular nucleus and the supraoptic nucleus. The differences in brain galanin expression between animals collected under both sets of environmental conditions indicated changes which occur during the annual and reproductive cycles. The wide hypothalamic and extrahypothalamic distribution of galanin immunoreactive fibers suggests that this peptide may have hypophysiotropic, neuromodulator and neurotransmitter roles in the lizard U. acanthinura. (Folia Histochemica et Cytobiologica 2013, Vol. 51, No. 1, 45-54)
\end{abstract}

Key words: Galanin, lizard, brain, reproduction, immunohistochemistry, environment, desert, U. acanthinura

\section{Introduction}

Galanin is a $29-30$ amino acid neuropeptide, which is present in the central nervous system (CNS) and peripheral tissues. Its primary structure is highly conserved among vertebrates (almost 90\%), indicating the importance of the neuropeptide. Galanin has multiple biological effects and many studies have demonstrated its involvement in several hypothalamic and hypophyseal functions including feeding, seizure, pain, learning, memory and depression [1]. This peptide seems also to be involved in the osmoregulatory response to water-restriction $[2,3]$. Galanin exerts neuroendocrine effects by modulating the release of

Correspondence address: S.B. Hammouche Aride Area Research Laboratory, Biological Sciences Faculty, University of Sciences and Technology of Houari Boumediene, P.B. 39, El-Alia, Bab Ezzouar, Algiers. Algeria; e-mail: sadjiah@yahoo.fr gonadotropins [4], prolactin [5], growth hormone [6] and somatostatin [7]. These regulatory actions of galanin are further supported by many reports that show galaninergic innervation of hypophyseal secretory cells in several vertebrate groups including mammals [8-11]. Moreover, the expression of galanin is elevated following estrogen administration, neuronal activation, denervation and/or nerve injury, as well as during development [1]. The use of immunohistochemical methods revealed a wide distribution of galanin in the brain of several vertebrate groups: mammals [12-15], birds [16, 17], reptiles [9, 18], amphibians [19-22] and fish [8, 23-25].

In the lizard $P$. s. sicula, galanin seemed to interact in the oviduct with estrogen, vasoactive intestinal polypeptide and oviposition [26] and its systemic administration was able to stimulate the thyroid gland both at morphological and physiological level [27]. However, there is no knowledge of the physiological role played by galanin in the CNS of reptiles. The galanin stimulates food intake in the goldfish C. au- 
Table 1. Weight, mouth cloaca length and sexual state of U.acanthinura used in the study

\begin{tabular}{|c|c|c|c|}
\hline \multicolumn{2}{|l|}{ March } & \multicolumn{2}{|l|}{ June } \\
\hline Mouth-cloaca length $[\mathrm{cm}]$ & Weight $[\mathrm{g}]$ & Mouth-cloaca length $[\mathrm{cm}]$ & Weight $[\mathrm{g}]$ \\
\hline 20/Adult $O^{\lambda}$ (beginning of spermatogenesis) & 314.5 & $\begin{array}{l}\text { 19/Adult } \sigma^{\pi} \text { (spermatogenesis) } \\
\text { 20.5/Adult } \sigma^{\top} \text { (spermatogenesis) }\end{array}$ & $\begin{array}{l}348 \\
295\end{array}$ \\
\hline $\begin{array}{l}\text { 18/Adult }+ \text { (previtellogenesis) } \\
\text { 18.2/Adult }+ \text { (previtellogenesis) }\end{array}$ & $\begin{array}{l}201.9 \\
221\end{array}$ & 22/Adult + (at the egg retention) & 371 \\
\hline $\begin{array}{l}\text { 17/Sub-adult } q \text { (immature) } \\
17.2 \text { Sub-adult } q \text { (immature) }\end{array}$ & $\begin{array}{l}175 \\
163\end{array}$ & $\begin{array}{l}\text { 17/Sub-adult } O^{1} \text { (immature) } \\
17.5 / \text { Sub-adult }{ }^{\lambda} \text { (immature) }\end{array}$ & $\begin{array}{l}154.3 \\
182.4\end{array}$ \\
\hline
\end{tabular}

ratus [28], while it does not affect feeding in the neonatal chicks [29]. Despite their crucial position among vertebrate phylogeny, there have been only two studies published on the distribution of galanin in a reptilian species, the turtle $M$. caspica [9] and the snake B. jararaca [18].

Although physiological data have been obtained about the role of galanin in the lizard, a deserticole and seasonal breeder, there are no data describing distribution of galaninergic system in the brain of lizard species. Therefore, we undertook study on the distribution of galanin throughout the entire brain of the $U$. acanthinura by means of immunohistochemistry.

\section{Material and methods}

Animals. Lizards $U$. acanthinura used in this study were collected during two periods of the active season, in March just before reproduction: adult male $(\mathrm{n}=1)$, adult female $(\mathrm{n}=2)$ and sub-adult female $(\mathrm{n}=2)$ and in early June after ovulation: adult male $(\mathrm{n}=2)$, sub-adult male $(n=2)$ and adult female with eggs retention $(n=1)$. Their weight and the mouth-cloaca length were summarized in the Table 1 . Animals were anesthetized by intraperitoneal injection of $25 \%$ urethane solution $(5,7 \mathrm{~mL} / \mathrm{kg}$ body weight $)$ and subsequently transcardially injected with $0,9 \% \mathrm{NaCl}$ solution. Specimens were then perfused with $4 \%$ paraformaldehyde in phosphate buffer $0.1 \mathrm{M}, \mathrm{pH} 7.4$ for 30 to $40 \mathrm{~min}$. The brains were removed and postfixed for $24 \mathrm{~h}$ in the same fixative, then they were cryoprotected in $30 \%$ sucrose in phosphate buffer $0.1 \mathrm{M}, \mathrm{pH} 7.4$ at $4^{\circ} \mathrm{C}$ during $24 \mathrm{~h}$. Afterwards, the fixed brains were frozen at $-40^{\circ} \mathrm{C}$, cut at $-20^{\circ} \mathrm{C}$ on a freezing microtome on serial frontal sections of $50 \mu \mathrm{m}$ thickness. The free-floating sections were collected in phosphate buffer $0.1 \mathrm{M}$, pH 7.4.

Immunohistochemistry. The serial frontal sections were immunostained according to indirect immunofluorescence method. Every free-floating section was pre-incubated in phosphate buffered saline $0.1 \mathrm{M}, \mathrm{pH} 7.4$ (PBS) containing $0.1 \%$ of gelatine and $0.3 \%$ of Triton (PBS-gelatine-Triton) for $1 \mathrm{~h}$ at $4^{\circ} \mathrm{C}$. They were then incubated overnight at $4^{\circ} \mathrm{C}$ in the primary antibody (polyclonal antiserum raised in rabbit against porcine galanin generously gift by Prof. M. Tramu, Bordeaux University, France) diluted 1:400 in PBS-gelatineTriton. After four washes (10 min each) in PBS, the sections were incubated at room temperature with the secondary antibody (IgG anti-rabbit FITC Dako, France) diluted 1:200 in PBS-gelatine-triton for 2-3 h. They were washed in PBS, spread and mounted in Mowiol (Calbiochem, France) and observed in epifluorescence microscope (Olympus, Japan) equipped with an excitation filter HQ480/40, dichroic filter Q505/lp, and emission filter HQ535/50 allowing to observe green fluorescence. The pictures were digitalized with D76 Olympus color camera coupled to microcomputer system with DP controller software.

The specificity of the rabbit serum anti-galanin has previously been evaluated and used to locate the galanin in the sheep diencephalon [12]. To check the specificity of the labeling, adjacent sections were incubated without primary antiserum.

The size of perkaryons, measured across the long axis of cell bodies, and diameter of nuclei were obtained in sections of $50 \mu \mathrm{m}$ thickness. The average (mean) and SD were obtained for 9 to 20 of cells per section and according to the total number of neurons observed for each area.

\section{Results}

The galanin immunoreactivity in lizard's brain showed bilateral symmetry. Since animals were killed at different times of the active period of the annual cycle, seasonal variations had to be evaluated.

\section{Neuronal perikarya}

Two areas with high densities of galanin immunoreactive neurons were observed in the brain of $U$. acanthinura. The first one was detected in the mediobasal hypothalamus in the infundibular recess nucleus (RIN), the nucleus of the paraventricular organ 
(NPO), the paraventricular organ (PO) and the posterior periventricular nucleus $(\mathrm{PPvN})$. The galanin immunoreactive perikarya were generally bipolar, large and mostly pear-shaped. The form of their nucleus varied between round and oval with the occurrence of a nucleolus. Some galaninergic perikarya displayed an apical process directed toward the ventricle. In the outer layer of the median eminence (ME), some immunoreactive perikarya were detected.

The second area of galanin-immunoreactive neurons, with lower density as compared to the first one, was present in the anterior hypothalamus, above the optic chiasma at the level of the anterior PvN (APvN), the paraventricular nucleus (PVN) and the supraoptic nucleus (SON). The majority of the periventricular galanin-immunoreactive perikarya displayed an apical process directed toward the ventricle. The SON exhibited a low to moderate density of the galanin neurons compared to $\mathrm{PvN}$. The immunoreactive perikarya were found close to the optic chiasma.

\section{Nerve fibers}

The galaninergic innervations were distributed throughout several brain parts of $U$. acantninura. In the telencephalon, bundles of galanin-immunoreactive fibers were seen in the nucleus accumbens and the septum in the dorsal septal nucleus, the median septal nucleus and the lateral septal nucleus. Some fibers were observed in the nucleus of the diagonal band of Broca and the striatum.

The diencephalon contained also abundant galanin fibers. In the anterior hypothalamus, galaninergic innervations were noted in $\mathrm{SON}, \mathrm{APvN}$ and in the PVN. In the mediobasal hypothalamus, RIN, NPO, $\mathrm{EM}$ and $\mathrm{PPvN}$ were generously innervated by galaninimmunoreactive fibers. Other diencephalic areas such as medial thalamic nucleus (MTN) and the subcommissural organ were also innervated by galanin fibers.

\section{Distribution of galanin-immunoreactive neurons in CNS at the previtellogenesis period (March)}

Infundibular recess nucleus (RIN) and nucleus of the paraventricular organ (NPO)

In adult male and females, the labeled perikarya without particular orientation were long $(14.73 \pm 0.085$ $\mu \mathrm{m})$ and their nucleus reached on average $8.42 \pm 0.041$ $\mu \mathrm{m}$ in diameter (Figures 1 and 2, and Table 2). The immunoreactive perikarya were abundant; their number reached 54 per section in an area of $8683 \mu \mathrm{m}^{2}$. Numerous varicosities were observed in theirs galaninergic fibers which were long and strongly labeled
(Figure 3). Some perikarya displayed an apical process directed toward the 3rd ventricle (Figure 4). We noted absence of labeling in the ependymal cells. At the level of PO, the galanin perikarya were localized parallel to each other, with a vertical orientation toward the wall of the 3rd ventricle with majority displaying an apical process directed toward the ventricle (Figure 5). At the level of ME, some immunoreactive perikarya were detected in the outer cellular layer (Figure 6). These last two structures were relatively less densely innervated by galaninergic fibers than in RIN and NPO.

In sub-adult females, the galanin-labeled perikarya appeared less numerous than in the adult animals (Figure 7), in fact, their number was about 29 per section in an area of $8683 \mu \mathrm{m}^{2}$, which was $53.7 \%$ less than in adult lizards. Also, the size of galanin-immunoreactive perikarya was slightly smaller (Figure 8), they had a length of $14 \pm 0.09 \mu \mathrm{m}$ and their nucleus presented an average diameter of $8.11 \pm 0.06 \mu \mathrm{m}$.

Anterior periventricular nucleus $(\mathrm{APvN})$ and paraventricular nucleus (PVN)

In adult male and females, the galanin-immunoreactive perikarya were abundant (Figures 9 and 10). In an area of $8683 \mu \mathrm{m}^{2}$, their number reached 51 per section. Some perikarya were round and other were pear-shaped. The labeled perikarya were larger than in the RIN and NPO. The length and the nucleus diameter were respectively $15.78 \pm 0.085 \mu \mathrm{m}$ and $9.12 \pm$ $\pm 0.03 \mu \mathrm{m}$. In the APvN, the apical process passed from perikarya between the ependymal cells to reach the lumen of the $3 \mathrm{rd}$ ventricle (Figure 11). The APvN and PVN were rich in galaninergic fibers which contained some varicosities.

In sub-adult females, the number of the galanin immunoreactive perikarya appeared to decrease compared to adult females (Figure 12 and 13). It reached 30 cells per $8683 \mu \mathrm{m}^{2}$ per section, indicating a reduction of $58.8 \%$. However, their size did not vary much, since the labeled perikarya and the nucleus measured $15.37 \pm 0.085 \mu \mathrm{m}$ and $8.93 \pm 0.02 \mu \mathrm{m}$, respectively. The appearance of galaninergic fibers was similar to those observed in APvN and PVN of adult male and females.

\section{Supraoptic nucleus (SON)}

In adult male and females, the galanin-immunoreactive perikarya were not numerous (Figure 14). There were 14 in an area of $8683 \mu \mathrm{m}^{2}$ per section. Their size was $14.29 \pm 0.02 \mu \mathrm{m}$ and the diameter of the nucleus was $8.59 \pm 0.05 \mu \mathrm{m}$.

In sub-adult females, the number of the galanin immunoreactive perikarya decreased (Figure 15), we 

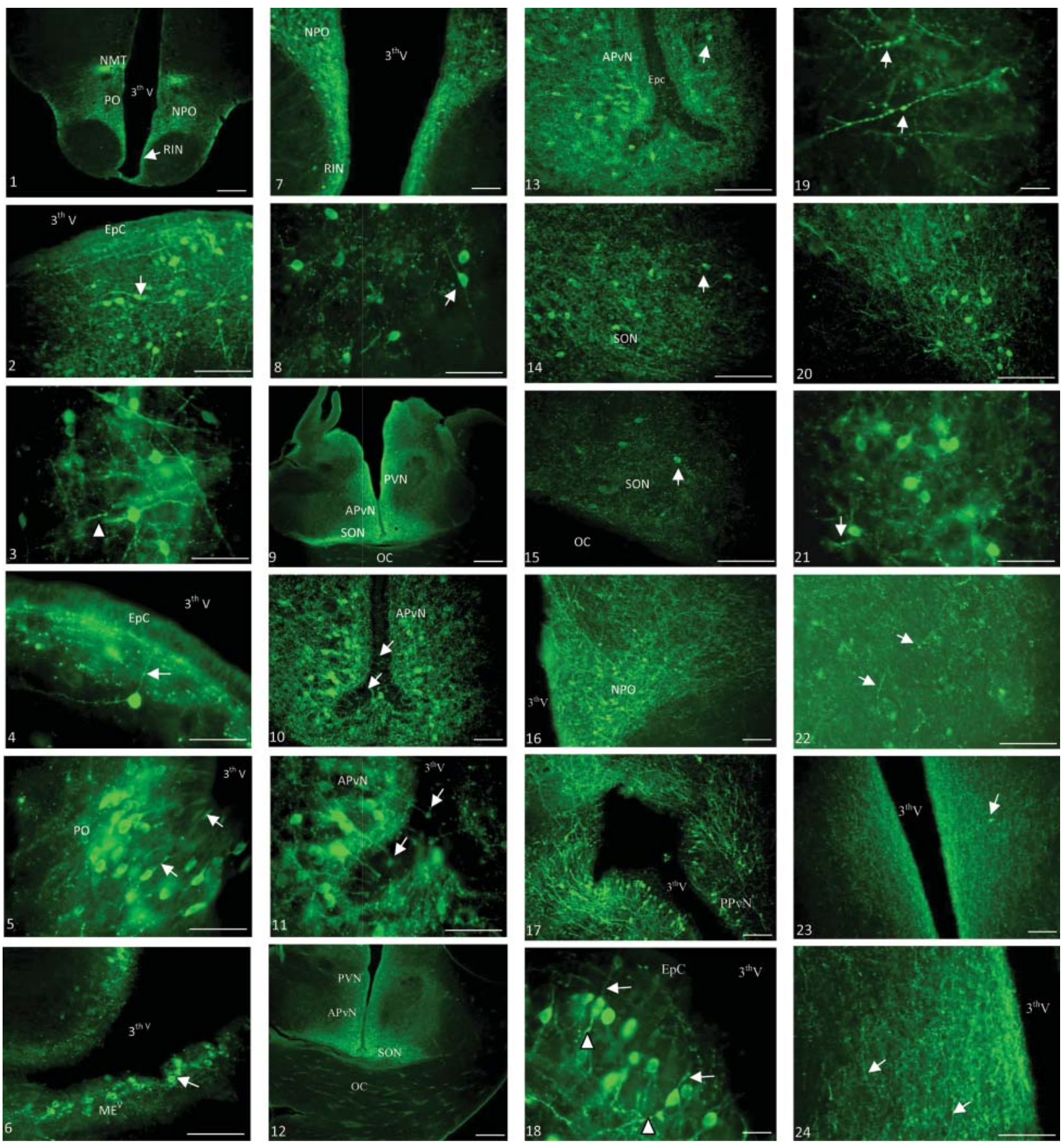

Galanin immunoreactivity in the brain of the desert lizard $U$. Acanthinura

\section{Observations in March}

Figure 1, 2, 3, 4, 5, 6. Adult female. The perikarya were detected in the RIN, NPO, PO and the fibers in the NMT (Figure 1). In the NPO and RIN, they were abundant (arrow) (Figure 2) and showed numerous varicosities in the long fibers (arrowhead) (Figure 3). Some perikarya displayed an apical process toward the 3 rd ventricle $\left(3^{\text {rd }} \mathrm{V}\right)$ (arrow) and the absence of labeling in the ependymal cells (EpC) could be noted (Figure 4). The perikarya in the PO with a vertical orientation displayed an apical process toward the $3^{\text {rd }} \mathrm{V}$ (arrows) (Figure 5). Cells were detected in the outer layer of ME (arrow) (Figure 6)

Figure 7, 8. Sub-adult female. Perikarya in the RIN and NPO were less numerous (Figure 7), atrophic and slightly labeled (arrow) (Figure 8)

Figure 9, 10, 11. Adult female. Note the intense labeling in the APvN and PVN (Figure 9). APvN with numerous perikarya (Figure 10) which displayed an apical process reaching the $3^{\text {rd }} \mathrm{V}$ (arrows) (Detail in Figure 11)

Figure 12, 13. Sub-adult female. Note the less intense labeling in the APvN and PVN (Figure 12). APvN with a reduced number of perikarya (arrow) (Figure 13) 
Figure 14. SON of adult female. Some perikarya (arrow) and abundant fibers with a few varicosities and intense signal were present

Figure 15. SON of sub-adult female. The number of perikarya (arrow) was reduced

\section{Observations in June}

Figure 16, 17, 18, 19. Female at eggs retention: NPO with a lower number and a cellular atrophy of labeled perikarya (Figure 16). In the PPvN, perikarya were numerous (Figure 17), with a vertical orientation, a larger size and an intense signal and showed a short cell processes contacting the cerebrospinal fluid (arrows), and a very long process which extended laterally (arrowheads) (Figure 18) with a strong staining varicosities (arrows) (Figure 19)

Figure 20, 21. Adult male: NPO with some small labeled perikarya (Figure 20) and a less intense staining in the fibers (arrow) (Figure 21)

Figure 22. Female at eggs retention: PVN shows only few fibers (arrows)

Figure 23, 24. Sub-adult male: Note one perikarya in the PVN (arrow) and the abundance of strongly stained fibers in the APvN (arrows) (Figure 24)

Scale bars: Figure $1(0.4 \mathrm{~mm})$, Figure $2(97.56 \mu \mathrm{m})$, Figure 3-5 $(52.62 \mu \mathrm{m})$, Figure $6(98.21 \mu \mathrm{m})$, Figure $7(97.92 \mu \mathrm{m})$, Figure $8(55.16 \mu \mathrm{m})$, Figure $9(0.44 \mathrm{~mm})$, Figure $10(51 \mu \mathrm{m})$, Figure $11(55.33 \mu \mathrm{m})$, Figure $12(0.4 \mathrm{~mm})$, Figure 13-15 $(95.28 \mu \mathrm{m})$, Figure 16-17 $(99.62 \mu \mathrm{m})$, Figure $18(25.82 \mu \mathrm{m})$, Figure $19(24.95 \mu \mathrm{m})$, Figure $20(92.35 \mu \mathrm{m})$, Figure $21(49.63 \mu \mathrm{m})$, Figure $22(90.89 \mu \mathrm{m})$, Figure $23(94.86 \mu \mathrm{m})$, Figure $24(91.7 \mu \mathrm{m})$

identified only 9 cells in an area of $8683 \mu \mathrm{m}^{2}$ per section. The length of the cell body and the nuclear diameter were $14.07 \pm 0.05 \mu \mathrm{m}$ and $8.44 \pm 0.08 \mu \mathrm{m}$, respectively. In all these animals, the galanin-immunoreactive fibers were abundant with a few varicosities and an intense signal.

\section{Distribution of galanin-immunoreactive neurons in CNS after vitellogenesis period (June)}

\section{RIN, NPO and PPvN}

In the female at the period of eggs retention, in the NPO and rostral and median parts of RIN, the galaninergic cell bodies showed a lower density and a cellular atrophy as compared with the adult male and females studied in March (Figure 16). Size and nucleus diameter were $12.10 \pm 0.14 \mu \mathrm{m}$ and $8.09 \pm 0.008 \mu \mathrm{m}$, respectively, with a labeling intensity lower compared to the previtellogenesis period, their number not exceeded 19 per section in an area of $8683 \mu \mathrm{m}^{2}$, corresponding to a reduction of $35.18 \%$. In the caudal part of RIN and PPvN, the distribution of the galaninergic cell bodies was very different (Figure 17). They were abundant and their number reached 41 per section in an area of $8683 \mu \mathrm{m}^{2}$. They had a larger size of $16.66 \pm 0.15 \mu \mathrm{m}$ with a nuclear diameter of $8.94 \pm$ $\pm 0.03 \mu \mathrm{m}$ with an intense labeling. The perikarya were vertically oriented running to the wall of the 3 rd ventricle and showed two main cell processes, one was short and approached the lumen of the ventricle, whereas the other one was very long and extended laterally (Figure 18). Numerous varicosities and a strong staining were observed in these galaninergic fibers (Figure 19).
In the adult and the sub-adult males, the immunoreactive cells become fewer compared to males captured in March. Particularly in adult males (Figure 20), the number was 24 per section in an area of $8683 \mu \mathrm{m}^{2}$. There was a cellular atrophy, cell size and nuclear diameter were smaller $(12.76 \pm 0.186 \mu \mathrm{m}$ and $7.04 \pm 0.066 \mu \mathrm{m}$, respectively). The labeling was reduced in most cell bodies and galaninergic fibers became less frequent with a less intense labeling as compared with adult male studied in March (Figure 21).

\section{APvN and PVN}

In the female at the period of eggs retention and adult males, the immunoreactive cell bodies were totally absent (Figure 22). In the sub-adult males, they were rare or absent (Figure 23). In the pregnant female, only few galaninergic fibers were observed. However, in the adult and sub-adult males, the APvN remained richly innervated by fibers strongly immunoreactive for galanin which contained few varicosities (Figure 24).

\section{SON}

In the female during the period of eggs retention and sub-adult males, the immunoreactive cell bodies were not present. In the adult males, they were rare to absent. With respect to galaninergic fibers, the observations were similar to those of the $\mathrm{APvN}$ studied at the same time of the annual cycle. An abundance of neurons was observed in the CNS during the active season of $U$. acanthinura just before reproduction in the adult male and females with neuronal populations localized in APvN, PVN, SON, NPO and RIN. Neurons in APvN and PVN appeared to be the more important in size at that time (Table 2). In the sub-adult 
Table 2. Number and size of galanin-immunoreactive neurons in the hypothalamic nuclei of $U$. acanthinura

\begin{tabular}{|c|c|c|c|c|c|}
\hline & \multirow[b]{2}{*}{ Animals } & \multicolumn{2}{|c|}{ Anterior hypothalamus } & \multirow{2}{*}{$\begin{array}{l}\text { Mediobasal hypothalamus } \\
\text { NPO + RIN }\end{array}$} \\
\hline & & & $\mathbf{A P v N}+\mathbf{P V N}$ & SON & \\
\hline \multirow{4}{*}{ 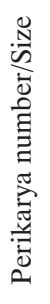 } & $\begin{array}{l}\text { March } \\
\text { (wet season) }\end{array}$ & $\begin{array}{l}q+0 \\
\text { Adults }\end{array}$ & $51 ; 15.78 \pm 0.085 \mu \mathrm{m}$ & $14 ; 14.29 \pm 0.023 \mu \mathrm{m}$ & $54 ; 14.73 \pm 0.085 \mu \mathrm{m}$ \\
\hline & & † Sub-adults & $30 ; 15.37 \pm 0.085 \mu \mathrm{m}$ & $9 ; 14.07 \pm 0.05 \mu \mathrm{m}$ & $29 ; 14 \pm 0.091 \mu \mathrm{m}$ \\
\hline & $\begin{array}{l}\text { June } \\
\text { (arid season) }\end{array}$ & q Adult & \multicolumn{2}{|l|}{ Rare/absent } & $\begin{array}{l}41 ; 16.66 \pm 0.154 \mu \mathrm{m} \mathrm{RINc}+\mathrm{PPvN} \\
19 ; 12.10 \pm 0.14 \mu \mathrm{m}\end{array}$ \\
\hline & & $\begin{array}{l}\text { Adults + } \\
\text { Sub-adults }\end{array}$ & \multicolumn{2}{|l|}{ Rare/absent } & $24 ; 12.76 \pm 0.186 \mu \mathrm{m}$ \\
\hline
\end{tabular}

RINc: caudal part of RIN, number of perikarya was measured in the area of $8683 \mu \mathrm{m}^{2}$ as described in Methods

females, the results were similar in the anatomical distribution of galaninergic neurons, only one significant difference was noted in the reduction of their number compared to adults and a very slight decrease in size was noted (Table 2). Galaninergic system was more developed in adults and no sexual dimorphism was observed.

In June, regardless of sex and sexual maturity of lizards studied, immunoreactivity disappeared from the anterior hypothalamus and persisted only in the mediobasal hypothalamus. However, variations were observed in this latter location between different animals (Table 2). In the adult males, there was a marked decrease in the number and cell size compared to the adult male before reproductive period, while in the subadult males just a cellular atrophy was observed compared to the sub-adult females of the pre-reproductive period (March). It is interesting to note that no difference was observed between adults and sub-adults males at this period, the galaninergic system appeared in the same way. Thus, seasonal variations were much larger in the adult males. In female at the eggs retention period, the results were conflicting. In NPO and rostral and median parts of RIN, a sharp reduction in the number and size was observed compared the female before vitellogenesis, whereas in the caudal part of RIN, the immunoreactive neurons undergone an abundant net cellular hypertrophy with the appearance of immunoreactivity in the PPvN (Table 2).

\section{Discussion}

This was the extensive study that determined the distribution of galanin-immunoreactive neurons and fibers in the brain of the lizard U. acanthinura. Colchicine is known to inhibit axoplasmic transport and thereby increase the level of neurotransmitter in the perikarya. However, colchicine may increase the expression of mRNA encoding galanin as demonstrated in the rat brain $[30,31]$, especially in the preoptic and lateral hypothalamic area. In order to not distort our results, treatment with colchicine has not been made.

An antiserum against anti-rabbit galanin was used to detect galanin peptide in the different parts of the brain in the colchicine-untreated U. acanthinura. The structure of galanin in alligator was more similar to that of sheep (three amino acid substitutions) than that of chicken (four amino acid substitutions) [32]:

\section{Chicken G W T L N S AGY L L G P H A V D N H RS F N D K H G F T \\ Alligator G W T L N S AGY L L G P H A I D N H RS F N E K H G I A \\ Mutton G W T L N S AGY L L GP H A I D N H RS F H D K H G L A}

The anti-galanin used in the present study has been used elsewhere in mammalian [12] and non-mammalian vertebrates, including the turtle $M$. caspica [9] and the snake B. jararaca [18].

To our knowledge, this was the first study on the distribution of galanin in a lizard brain. The comparison between the snake $B$. jararaca [18] and the lizard $U$. acanthinura (present study) revealed notable differences. Since the same anti-galanin and anti-rabbit IgG sera were employed in both studies, these differences could not be attributed to the applied staining method.

In the lizard $U$. acanthinura, the galanin immunoreactive neurons were localized in the anterior and mediobasal hypothalamus. Consequently, these neurons would be the origin of all galaninergic fibers observed throughout the brain. The distribution of these galanin perikarya was wider than that described in a snake where the immunoreactive neurons were exclusively found in the RIN [18].

The anatomical localization of galanin immunoreactivity in the brain of the lizard U. acanthinura ap- 
peared to resemble that of mammals rather than that of the snake or other lower vertebrate. In fact, in fish, the perikarya have been identified in the preoptic and tuberal hypothalamus [8, 23-25, 33]. In amphibians [19, 20], birds [16, 17] and chelonian [9], galanin-Ir neurons were found in the hypothalamus, telencephalon, mesencephalon and rombencephalon. In mammals, the galanin-Ir cell bodies were widely distributed in the CNS, particularly in the hypothalamus in the preoptic area, the infundibular/arcuate nucleus, the mediobasal hypothalamus, and periphery of the supraoptic and the paraventricular nuclei $[12,13,15,34,35]$.

It seems likely that the number of brain nuclei containing galanin perikarya increases along the vertebrate tree. The limited anatomical distribution of galanin perikarya in the snake $B$. jararaca [18] compared to $U$. acanthinura was unexpected but could be related to the different physiological status of animals.

The distribution of galanin-Ir neurons in lizard presented some interesting characteristics. Differences in galanin expression between females collected under both sets of environmental conditions indicate changes during the reproductive cycle.

\section{Anterior hypothalamus}

The lack of galanin in the PVN, APvN and SON in all lizards captured in June, arid season, and its expression in March, wet season, would be related to hydromineral balance. The SON and PVN of the hypothalamus contain magnocellular neurons that synthesize vasopressin, which regulates fluid balance by means of its antidiuretic action on the kidney.

At the end of hibernation and after the winter rains in March, the vegetation is available which will allow the animal to resume normal physiological activity after a long period of basal metabolism. U. acanthinu$\mathrm{ra}$ is herbivore and the vegetation is its only source of water. The SON in this species could induce the biosynthesis and storage of galanin. In June, the vegetation is scarce and the animal remains at the bottom of its burrow. This state of restriction could induce the rapid synthesis and release of galanin. Indeed, in a semi-arid rodent $T$. gracilis, $w$ hich pseudoestivates, water deprivation induced an increase in the biosynthesis and storage of both the vasopressin and galanin by cons in another rodent semi-arid $S$. caurinus, which estivates, the restriction of water implies a decrease in storage of the two peptides but not their synthesis, resulting in a rapid release [3]. As these two peptides show similar patterns of change in response to water deprivation, suggesting the involvement of galanin in the control of body water balance, probably via the neuromodulation of vasopressin secretion
[3]. In mammals, there are evidences indicating a physiological role of galanin as a neurotransmitter involved in the inhibition of vasopressin release [3638]. Other findings may support our interpretation, it is Fernandez-Llebrez et al. [39] who showed that dehydration in reptiles involved a decrease in the affinity of the AVT perikarya (equivalent to vasopressin) to the Weat-germ agglutinin (WGA), while AVT axons continued to bind strongly to WGA. This observation suggests that under conditions of water restriction, the transport of AVT from perikarya to the axon could be accelerated. Our study supports this hypothesis since in SON and PVN of $U$. acanthinura only galanin-Ir fibers and not perikarya were immunolabeled.

Failure to maintenance the richness of the galaninergic fibers in these CNS parts in the female during eggs retention compared to adult and sub-adult males was unexpected. However, it can be hypothesized that during eggs retention, the AVT which stimulates the secretion of prostaglandin $\mathrm{E}_{2}$ and $\mathrm{PGF}_{2}$ alpha, and smooth muscle contraction of the oviduct [40] would not be synthesized in large amount which would be reflected by a decrease in the synthesis of galanin and prevented an early oviposition. A recent study conducted in the chicken supports our hypothesis [41]. Klein and Grossman showed that within SON neurons, AVT immunoreactivity increased before oviposition and decreased after oviposition while the galanin immunoreactivity increased significantly immediately after oviposition, thus the galanin acted to limit AVT release in the SON [41].

The difference in the galanin immunoreactivities obtained between wet season and arid season in U. acanthinura may reflect differential functions of this hypothalamic neurotransmitter in controlling nutrient ingestion at different periods of the annual cycle. Indeed, the feeding response elicited by the galanin treatment in the PVN [42] and in the APvN and the adjacent periventricular region [43] was demonstrated in rat. In obese rats, galanin amount was more than doubled in the PVN and SON compared to lean animals [44].

\section{Mediobasal hypothalamus}

The location of galanin perikarya in the infundibular hypothalamus strongly suggests that this peptide may participate in the regulation of feeding behavior in $U$. acanthinura. The high expression of galanin wet season (March) and relatively low in arid season (June) argues for a food intake stimulatory effect in $U$. acanthinura. Indeed, galanin was found to be involved in the central regulation of feeding [28, 45]. On the other hand, the importance of the galanin in March, just before reproduction, may instead reflect 
a sexual interaction with the function. It was observed that galanin stimulates GnRH system [46] and the secretion of gonadotropins $[4,47,48]$ either by a direct action on GnRH neurons [49,50] or indirectly by inhibiting beta endorphin neurons [51].

In June, the maintenance of the galanin immunoreactivity exclusively in the caudal part of RIN and its appearance in the $\mathrm{PPvN}$ during eggs retention while it decreases in the other regions of the brain and in all nuclei of the adult males suggests that CNS regions could be involved in the sexual function and their solicitation could allow a normal eggs retention. The galanin could allow the release of the prolactin necessary to corpus luteum activity. Indeed, the stimulatory effect of galanin on the secretion of prolactin was shown in rat [5]. The overexpression of galanin in these parts during the eggs retention can exert a positive feedback effect of estradiol since in rat estradiol stimulated the galanin expression [49].

\section{Telencephalon}

The absence of galaninergic perikarya in the telencephalon of the $U$. acanthinura was unexpected but agrees with results obtained in the snake [18] and turtle [9] and differs from those found in amphibians $[19,20]$, birds $[16,17]$ and mammals $[12,13,15]$ where the immunoreactive neurons were detected in the septum. This latter is supposed to be involved in the regulation of the water balance $[52,53]$. The presence of a bundle of galanin fibers in the septum and nucleus accumbens of $U$. acanthinura indicates that this peptide may affect septal function in this lizard. The widespread distribution of galanin fibers as noted in other reptiles $[9,18]$, supports suggested roles played by this peptide.

In $U$. acanthinura, abundant galanin neurons with processes contacting the $3 \mathrm{rd}$ ventricle were detected in the hypothalamus as in turtle [9], amphibians [22] and fish [25], whereas cells expressing thyrotropin releasing hormone were described in reptiles [54]. These cerebrospinal fluid-contacting cells might be related to the non-synaptic signal transmission in brain [55]. These neurons may also regulate various processes in the hypothalamus, control changes in the chemical composition of the cerebrospinal fluid or secretion of galanin into the cerebrospinal fluid.

We demonstrated that galaninergic system of the desert lizard $U$. acanthinura was more developed in adults and was subjected to seasonal changes. Seasonal variations in the APvN, PVN and SON involving all lizards studied, the crackdown of galanin immunoreactivity in June would suggest an interrelationship with the annual cycle while those of the NPO and the RIN mainly affecting the male and female adults were related not only to the annual cycle (since size reduction in sub-adult) but also the reproductive cycle (reduction in the size and number in adults). The increase of the immunoreactivity exclusively in the caudal part of RIN and PPvN during eggs retention while its density decreased in the other regions of brain compared to adult males could allow a steroid synthesis during the eggs retention.

In conclusion, in the study of the galaninergic system in the brain of $U$. acanthinura we demonstrated that this system develops from the immature stage to mature stage. It was subjected to seasonal variations in the NSO and NPV suggestive that galanin may be involved in the control of body water balance. However, the changes observed in the mediobasal hypothalamus suggest that galanin may also be linked to the control of feeding behavior and reproductive functions. The wide distribution of galanin immunoreactive fibers in the brain of $U$. acanthinura suggests an important role of this peptide in functions of the CNS.

\section{Author's contributions}

SBH carried out the experiments, wrote and corrected the manuscript. MB corrected the manuscript. Authors read and approved the final manuscript.

\section{Acknowledgments}

The study is a part of research works realized in the item 3 of Arid Area Research Laboratory, Biological Sciences Faculty of Houari Boumediene Sciences and Technology University, Algiers. A part of the financial support through the Pharmacology, Neurobiology and Comportement Laboratory of University of Cadi Ayyad, Marrakech, is gratefully acknowledged.

\section{References}

1. Vrontakis ME. Galanin: A Biologically Active Peptide. Curr Drug Targets Neurol Disord. 2002;1:531-541.

2. Koenig JI, Hooi S, Gabriel SM, Martin JB. Potential involvement of galanin in the regulation of fluid homeostasis in the rat. Reg Pept. 1989;24:81-86.

3. Lacas-Gervais S, Maurel D, Hubert F, Allevard AM, Doukary A, Maggi V, Siaud P, Gharib C, Sicard B, Calas A, Hardin-Pouzet $\mathrm{H}$. Vasopressin and galanin expression in the hypothalamus of two African rodents, Taterillus gracilis and Steatomys caurinus, subjected to water-restriction. Gen Comp Endocrinol. 2003;133:132-145.

4. Estienne MJ, Barb C.R. The control of adenohypophysial hormone secretion by amino acids and peptides in swine. Domest Anim Endocrinol. 2005;29:34-42.

5. Koshiyama H, Kato, Y, Murakami Y, Ishikawa Y, Yanaihara N, Imura $\mathrm{H}$. Central galanin stimulates pituitary prolactin secretion in rats: possible involvement of hypothalamic vasoactive intestinal polypeptide. Neurosci Lett. 1987;75:49-54. 
6. Murakami I, Kato Y, Koshiyama H, Inoue T, Yanaihara N, Imura H. Galanin stimulates growth hormone $(\mathrm{GH})$ secretion via GH releasing factor (GRF) in conscious rats. Eur $J$ Pharmacol. 1987;136:415-418.

7. Aguila MC, Marubayashi U, McCann SM. The effect of galanin on growth hormone-releasing factor and somatostatin release from median eminence fragments in vitro. Neuroendocrinology. 1992;56:889-894.

8. Olivereau M, Olivereau JM. Immunocytochemical localization of a galanin-like peptidergic system in the brain and pituitary of some teleost fish. Histochemistry. 1991;96:343-354.

9. Jiménez AJ, Mancera JM, Pérez-Fígares JM, Fernández-Llebrez P. Distribution of galanin-like immunoreactivity in the brain of the turtle Mauremys caspica. J Comp Neurol. 1994;349:73-84.

10. Liu S, Gao J. The relationship of galanin immunoreactive nerve fibers to glandular cells in the anterior pituitary in the monkey. Brain Res. 1998;781(1-2):112-118.

11. Liu S. Galanin immunoreactive innervations of the anterior pituitary in the monkey and the dog. Brain Res. 2002;924:46-55.

12. Chaillou E, Tramu G, Tillet Y. Distribution of galanin immunoreactivity in the sheep diencephalon.J Chem Neuroanat. 1999;17:129-146.

13. Perez SE, Wynick D, Steiner RA, Mufson EJ. Distribution of galaninergic immunoreactivity in the brain of the mouse. J Comp Neurol. 2001;434:158-185.

14. Kukko-Lukjanov TK, Panula P. Subcellular distribution of histamine, GABA and galanin in tuberomamillary neurons in vitro. J Chem Neuroanat. 2003;25:279-292.

15. Okere $\mathrm{ChO}$, Waterhouse $\mathrm{BD}$. Inter- and intra-nuclear differences in galanin expression between the hypothalamic paraventricular and supraoptic nuclei in colchicine untreated rats. Brain Res. 2003;972:222-228.

16. Jozsa R, Mess B. Galanin-like immunoreactivity in the chicken brain. Cell Tissue Res. 1993;273:391-399.

17. Azumaya Y, Tsutsui K. Localization of galanin and its binding sites in the quail brain. Brain Res. 1996;727(1-2):187-195

18. Alponti RF, Mancera JM, Martín-del-Río MP, Silveira PF. Galanin-like immunoreactivity in the brain of the snake Bothrops jararaca. Gen Comp Endocrinol. 2006;149:269-277.

19. Lazar G, Liposits Z, Toth P, Trasti SL, Maderdrut JL, Merchenthaler L. Distribution of galanin-like immunoreactivity in the brain of Rana esculenta and Xenopus laevis.J Comp Neurol. 1991;310:45-67.

20. Olivereau M, Olivereau JM. Immunocytochemical localization of a galanin-like peptidergic system in the brain of two urodele and two anuran species (Amphibia). Histochemistry. 1992;98:51-66.

21. Gonzalez-Nicolini MV, Orezzoli AA, Villar MJ. An immunohistochemical study of temperature-related changes in galanin and nitric oxide synthase immunoreactivity in the hypothalamus of the toad. Gen Comp Endocrinol. 1998;110:175-181.

22. Heer T, Yovanovich CA, Pozzi AG, Paz DA. Galanin: Presence and distribution in the brain and pituitary of Rhinella arenarum (Amphibia: Anura) during development. Tissue Cell. 2008;40:333-342.

23. Batten TFC, Moons L, Cambre M, Vandesande F. Anatomical distribution of galanin-like immunoreactivity in the brain and pituitary of teleost Fishes. Neurosci Lett. 1990;111:12-17.

24. Rodriguez-Gomez FJ, Rendon-Unceta MC, Sarasquete C, Munoz-Cueto JA. Localization of galanin-like immunoreactive structures in the brain of the Senegalese sole, Solea senegalensis. Histochem J. 2000;32:123-131.
25. Adrio F, Rodriguez MA, Rodriguez-Moldes I. Distribution of galanin-like immunoreactivity in the brain of the Siberian sturgeon (Acipenser baeri). J Comp Neurol. 2005;487:54-74.

26. Lamanna C, Assisi L, Costagliola A, Vittoria A, Botte V, Cecio A. Galanin in the lizard oviduct: Its distribution and relationships with estrogen, VIP and oviposition. Life Sci. 1999;65:91-101.

27. Sciarrillo R, Capaldo A, Valiante S, Laforgia V, De Falco M. Localization and role of galanin in the thyroid gland of $P_{O}$ darcis sicula lizard (Reptilia, Lacertide). J Exp Zool A Ecol Genet Physiol. 2009; 311:199-206.

28. De Pedro N, Cespedes MV, Delgado MJ, Alonso-Bedate M. The galanin-induced feeding stimulation is mediated via alpha 2-adrenergic Receptors in goldFsh. Reg Pept. 1995;57:77-84.

29. Ando R, Bungo T, Kanwakami S, Shimojo M, Masuda Y, Furuse M. Intracerebroventricular injection of Mammalian motilin, melanin-concentrating hormone or galanin does not stimulate food intake in neonatal chicks. Br Poult Sci. 2000;41:508-511.

30. Giorgi S, Forloni G, Amoroso D, Consolo S. Expression of GAL mRNA in rat hypothalamus: effect of frontal deafferentation and colchicine treatment. Mol Brain Res. 1992;14: $277-281$.

31. Xu Z, Cortés R, Villar M, Morino P, Castel MN, Hökfelt T. Evidence for upregulation of galanin synthesis in rat glial cells in vivo after colchicine treatment. Neurosci Let. 1992;145:185-188.

32. Wang Y, Conlon JM. Purification and primary structure of galanin from the alligator stomach. Peptides. 1994;15:603-606.

33. Anglade I, Wang Y, Jensen J, Tramu G, Kah O, Conlon M. Characterization of trout galanin and its distribution in trout brain and pituitary. J Comp Neurol. 1994;350:63-74.

34. Skofitsch G, Jacobowitz DM. Immunohistochemical mapping of galanin-like neurons in the rat central nervous system. Peptides. 1985;6:509-546.

35. Gentleman SM, Falkai P, Bogerts B, Herrero MT, Polak JM, Roberts GW. Distribution of galanin-like immunoreactivity in the human brain. Brain Res. 1989;505:311-315.

36. Kondo K, Murase T, Otake K, Ito M, Oiso Y. Centrally administered galanin inhibits osmotically stimulated arginine vasopressin release in conscious rats. Neurosci Lett. 1991;128:245-248.

37. Landry M, Roche D, Calas A. Short-term effects of centrally administered galanin on the hyperosmotically stimulated expression of vasopressin in the rat hypothalamus an in situ hybridization and immunohistochemistry study. Neuroendocrinology. 1995;61:393-404.

38. Izdebeska K, Ciosek J. Galanin influences on vasopressin and oxytocin release: In vitro studies. Neuropeptides. 2010;44:341-348.

39. Fernandez-Llebrez P, Bernal AML, Rodriguez EM, Perez J1, Andrades JA, Grondona JM, Mancera JM, Perez-Figares JM. Colloid droplets in the magnocellular secretory neurons of the reptilian hypothalamus: An immunocytochemical and lectin-histochemical study. Cell Tissue Res. 1990;260:69-76.

40. Guillette LJJr, Demarco V, Palmer BD, Masson GR. Effects of arachidonic acid, prostaglandin F2, prostaglandin E2, and arginine vacotocin on induction of birth in vivo and in vitro in a viviparous lizard (Sceloporus jarrovi). Gen Comp Endocrinol. 1992;85:477-485.

41. Klein S, Grossmann R. Galanin immunoreactivity increased in chicken supraoptic neurons after activation of the vasotocin system at oviposition. Comp Biochem Physiol A: Mol Integr Physiol. 2008;149:411-419. 
42. Tempel DL, Leibowitz SF. Diurnal variations in the feeding responses to norepinephrine, neuropeptide $\mathrm{Y}$ and galanin in the PVN. Brain Res Bull. 1990;25:821-825.

43. Kyrkouli SE, Stanley BG, Seirafi RD, Leibowitz SF. Stimulation of feeding by galanin: Anatomical localization and behavioral specificity of this peptide's effects in the brain. Peptides. 1990;11:995-1001.

44. Beck B, Burlet A, Nicolas JP, Burlet C. Galanin in the hypothalamus of fed and fasted lean and obese Zucker rats. Brain Res. 1993;623:124-130.

45. Gundlach AL. Galanin/GALP and galanin receptors: role in central control of feeding, body weight/obesity and reproduction? Eur J Pharmacol. 2002;440:255-268.

46. Rossmanith WG, Clifton DK, Steiner RA. Galanin gene expression in hypothalamic GnRH-containing neurons of the rat: a model for autocrine regulation. Horm Metab Res. 1996;28:257-266.

47. Sahu A, Crowley WR, Tatemoto K, Balasubramaniam A, Kalra SP. Effects of neuropeptide Y, NPY analog (norleucine4-NPY), galanin and neuropeptide $\mathrm{K}$ on LH release in ovariectomized (ovx) and ovx estrogen, progesterone-treated rats. Peptides. 1987;8:921-926.

48. Sanchez-Criado JE, Bellido R, Aguilar JC, Garrido-Gracia JC. Antiprogestin RU486 blunts the stimulatory effect of galanin on LH secretion from rat pituitaries in vitro in an estrous cycle stage-dependent manner. Neurosci Lett. 2001;305:73-75.
49. Finn PD, Clifton DK, Steiner RA. The regulation of galanin gene expression in gonadotropin-releasing hormone neurons. Mol Cel Endocrinol. 1998;140:137-142.

50. Dufourny L, Skinner DC. Distribution of galanin receptor 1immunoreactive neurons in the ovine hypothalamus: colocalization with GnRH. Brain Res. 2005;1054:73-81.

51. Bouret S, Croix D, Mariot M, Loyens A, Prevot V, Jegou S, Vaudry H, Beauvillain JC, Mitchell V. Galanin modulates the activity of proopiomelanocortin neurons in the isolated mediobasal hypothalamus of the male rat. Neuroscience. 2002;112:475-485.

52. Miselis RR. The efferent projections of the subfornical organ of the rat: A circumventricular organ within a neural network subserving water balance. Brain Res. 1981;230:1-23.

53. Tanaka J, Saito H, Seto K. Involvement of the septum in the regulation of paraventricular vasopressin neurons by the subfornical organ in the rat. Neurosci Lett. 1988;92:187-191 .

54. Lopez JM, Dominguez L, Gonzalez A. Immunohistochemical localization of thyrotropin-releasing hormone in the brain of reptiles. J Chem Neuroanat. 2008;36:251-263.

55. Vígh B, Manzanoe Silva MJ, Frank CL, Vincze C, Czirok SJ, Szabó A, Lukáts A, Szél A. The system of cerebrospinal fluid-contacting neurons. Its supposed role in the nonsynaptic signal transmission of the brain. Histol Histopathol. 2004;19: $607-628$.

Submitted: 23 January, 2012 Accepted after reviews: 13 March, 2013 